\title{
Dialektika Sains, Tradisi dan al-Qur'an: Representasi Modernitas dalam Tafsir Rahmat karya Oemar Bakry
}

(Dialectic of Science, Tradition and the Qur'an: Representation of Modernity in Tafsir Rahmat by Oemar Bakry)

\section{Mahbub Ghozali}

UIN Sunan Kalijaga Yogyakarta, Indonesia

mahbub.ghozali@uin-suka.ac.id

DOI: $10.29240 /$ alquds.v5i2.3394

Submitted: 2021-09-03 | Revised: 2021-10-02 | Accepted: 2021-11-30

\begin{abstract}
The problem of interpretation in Indonesia which still refers to popular variation works impacts other understanding works ignored. This rejection has implications for the lack of disclosure of the peculiarities of an interpretation that can contribute to determining the method of interpretation in Indonesia. Tafsir Rahmat by Oemar Bakry is one of the interpretations that are rarely expressed in its content so that aspects of modernity are not revealed. This study aims to show parts of modernity in the Tafsir Rahmat in the form of dialectics between science, tradition, and the Qur'an. This research uses qualitative methods with content analysis as a data analysis tool. This research shows that Bakry provided a different view in the translation process by using modern terms to offer a breadth of understanding and ease. Science and technology are used to find wisdom (hikmah) and proving the truth of the Quran. The spirit of renewal carried by Bakry is also evident from the critical response to the traditions carried out by the people of Indonesia. The peculiarities in interpretation and translation that Bakry did were enough to make Tafsir Rahmat an object of study for dialectics to occur among researchers. It also impacts the dissemination of the content of this interpretation faster and affects the popularity of Tafsir Rahmat.
\end{abstract}

Keyword: Tafsir Rahmat; Oemar Bakry; Modernity

Abstrak. Problem penafsiran di Indonesia yang masih mengacu pada karya tafsir populer berdampak pada penelitian atas karya tafsir lain diabaikan. Pengabaian ini berimplikasi pada minimnya pengungkapan kekhasan suatu tafsir yang dapat memberikan sumbangan dalam menentukan metode penafsiran di Indonesia. Tafsir Rabmat karya Oemar Bakri merupakan salah satu tafsir yang jarang diungkapkan kandungannya, sehingga aspek modernitas yang terkandung di dalamnya tidak terungkap. Oleh sebab itu, penelitian ini bertujuan untuk mengungkapkan aspek modernitas dalam Tafsir Rahmat dalam bentuk dialektika antara sains, tradisi dan al-Qur'an. Penelitian ini menggunakan metode kualitatif dengan content analysis sebagai perangkat analisa data. Penelitian ini 
menunjukkan bahwa Bakry memberikan pandangan berbeda dalam proses penerjemahan dengan menggunakan istilah modern untuk memberikan keluasan pemahaman dan kemudahan. Perkembangan sains dan teknologi digunakan untuk mengungkapkan hikmah dan sebagai sarana pembuktian kebenaran al-Qur'an. Semangat pembaharuan yang diusung Bakry juga tampak dari tanggapan kritis terhadap tradisi yang dilakukan oleh masyarakat Indonesia. Kekhasan dalam aspek interpretasi dan penerjemahan yang dilakukan Bakry cukup untuk menjadikan Tafsir Rahmat sebagai objek kajian agar terjadi dialektika di antara para peneliti. Hal ini juga berdampak pada desiminasi atas kandungan tafsir ini lebih cepat dan berdampak pada popularitas Tafsir Rahmat.

Kata Kunci : Tafsir Rahmat; Oemar Bakry; Modernitas.

\section{Pendahuluan}

Popularitas suatu tafsir masih menjadi problem utama untuk menarik kandungan makna yang terdapat di dalamnya. ${ }^{1}$ Popularitas menjadi ukuran di luar problem akademis yang muncul. Kecenderungan ini berdampak pada keterbatasan pengungkapan kandungan tafsir di Indonesia yang hanya terfokus pada tafsir yang populer di kalangan peneliti, sehingga kajian atasnya tidak berlangsung secara maksimal dan cenderung repetitif. ${ }^{2}$ Tafsir Rahmat karya Oemar Bakry, dalam aspek ketersediaan naskah, dapat dikategorikan sebagai tafsir yang banyak dikenal dengan selalu disebut oleh para pengkaji. Tetapi, pengungkapan atas aspek-aspek penafsiran ataupun penerjemahan yang khas selalu ditinggalkan. Keterbatasan kajian tentang tafsir ini dimungkinkan bersumber dari kesulitan untuk mengungkapkan problem akademis dalam narasi yang diberikan Bakry, sehingga penjelasan tentang kecenderungan modernitas dalam tafsir ini tidak diungkapkan secara mendetail. Bakry menampilkan banyak narasi-narasi, baik dalam penerjemahan maupun dalam penafsiran dengan mengaitkan pemaknaan menggunakan istilah-istilah keilmuan modern. Aspek ini menjadi dasar untuk

${ }^{1}$ N. K. Farooqui, Mohammed Fauzan Noordin, dan Roslina Othman, "Ontology matching: A case of English translation of Al-Quran Tafsir," in Proceedings - International Conference on Information and Communication Technology for the Muslim World 2018, ICT4M 2018 (Institute of Electrical and Electronics Engineers Inc., 2018), 1-6, https://doi.org/10.1109/ICT4M.2018.00010; Thoriqul Aziz, Ahmad Zainal Abidin, dan Muthmainnatun Nafiah, "Tafsir Nusantara dan Isu-isu Global: Studi Kasus Relevansi Pemikiran Hamka tentang Keadilan Sosial, Kesetaraan Gender dan Pluralisme," Refleksi 19, no. 2 (30 November 2020), https://doi.org/10.15408/REF.V19I2.16791; Sayyida Sayyida et al., "Literature Qur'an in Indonesia: Tafsir Al-Qur'an H. Zainuddin Hamidy And Fachruddin HS (Has Analysis Of The Philological Approach)," in ICIIS (Jakarta, 2020), https://doi.org/10.4108/EAI.20-102020.2305183.

${ }^{2}$ Jika dilakukan penelusuran hasil penelitian dari rentang 2017-2021 dengan objek kajian Tafsir al-Misbah, maka ditemukan sepuluh ribu lebih judul yang membahas tentang tafsir ini dengan beragam model dan kesamaan pokok pembahasan. Tema yang sama dibedakan dengan perbedaan pada narasi judul, misalnya pembahasan moderasi Islam dibedakan dengan pembahasan konsep wasatiyah dan ummatan wasatan. Begitu juga, aspek tentang pandangan Shihab mengenai perempuan banyak dilakukan pengulangan tanpa menampilkan ide dan gagasan baru. 
mengenalkan dan mengungkapkan sisi modernitas dalam Tafsir Rabmat yang diabaikan oleh peneliti terdahulu.

Penelitian terdahulu mengabaikan gagasan Bakry dalam menggunakan sains untuk menjelaskan kandungan al-Qur'an. Studi yang menempatkan Tafsir Rahmat sebagai objek materiilnya membatasi pada identifikasi metode yang digunakan. Adekayanti menyimpulkan bahwa Tafsir Rabmat merupakan tafsir yang menggunakan metode Ijmälì (global) dengan menggunakan bahasa populer yang secara sistematika penulisan masuk dalam kategori non-ilmiah. ${ }^{3}$ Sementara para peneliti lain meninggalkan tafsir ini dan hanya digunakan sebagai pelengkap dalam kajian tafsir di Indonesia secara umum. Gusmian menyebut tafsir ini dalam penelitiannya sebagai tafsir dalam kategori karya yang ditulis oleh penafsir yang aktif di lingkungan pendidikan (madrasah). ${ }^{4}$ Dalam penelitian Tamam ${ }^{5}$ dan Latif ${ }^{6}$, tafsir ini dikategorikan sebagai bagian dari karya terjamah dan tafsir kontemporer. Dalam penelitian lain, Baihaki ${ }^{7}$ dan Hussin ${ }^{8}$ menyebut Tafsir Rabmat sebagai model karya terjemah. Pengabaian atas kandungan yang terdapat dalam tafsir ini berdampak pada pengungkapan cara dan penggunaan sains yang berdialektika dengan tradisi dan al-Qur'an tidak pernah dikenalkan.

Sejalan dengan itu, penelitian ini hendak menunjukkan kekhasan Tafsir Rahmat yang mengusung semangat modernitas dalam penerjemahan dan penjelasan terhadap ayat. Tujuan penulisan menunjukkan bagaimana Bakry, sebagai salah satu tokoh pembaharu Islam yang mengintegrasikan keilmuan modern dalam sistem keilmuan Islam menguatkan analisa penafsiran dengan menggunakan sains. Sejalan dengan itu, penelitian ini menunjukkan tiga bukti adanya proses modernisasi dalam Tafsir Rabmat, dorongan terhadap penguasaan ilmu al-Qur'an yang dihasilkan dari pemahaman ayat, penggunaan istilah modern dalam penerjemahan, dan responsnya terhadap keberadaan tradisi dalam praktik ibadah. Keberadaan bukti yang terdapat dalam Tafsir Rabmat dieksplorasi dalam

${ }^{3}$ Sri Adekayanti, "Metodologi Penafsiran Oemar Bakry (Studi Kitab Tafsir Rahmat)" (UIN Sunan Kalijaga Yogyakarta, 2007).

${ }^{4}$ Islah Gusmian, "Tafsir al-Qur'an di Indonesia: Sejarah dan Dinamika," Nun: Jurnal Studi Alquran dan Tafsir di Nusantara 1, no. 1 (2015), https://doi.org/10.32459/NUN.V1I1.8.

5 Ahmad Badrut Tamam, "Model Penelitian Tafsir; Studi Karya Howard M. Federspiel:," Madinab: Jurnal Studi Islam 5, no. 2 (2018): 125 - 138-125 - 138, http://ejournal.iaitabah.ac.id/index.php/madinah/article/view/275.

${ }^{6}$ Abd Latif, "Spektrum Historis Tafsir al-Qur'an di Indonesia," At-Tibyan 3, no. 1 (2020): 55-69, https://doi.org/10.30631/ATB.V3I1.14.

${ }^{7}$ Egi Sukma Baihaki, "Penerjemahan Al-Qur'an: Proses Penerjemahan al-Qur'an di Indonesia," Jurnal Ushuluddin 25, no. 1 (2017): 44, https://doi.org/10.24014/jush.v25i1.2339.

${ }^{8}$ Mohamad Hussin dan Muhammad Hakim Kamal, "Translation of al-Quran into Malay Language in the Malay World," IJISH (International Journal of Islamic Studies and Humanities) 4, no. 1 (2021): 32-50, https://doi.org/10.26555/IJISH.V4I1.3322. 
tulisan ini melalui pengungkapan secara deskriptif, kritis, dan impliklatif untuk menunjukkan kekhasan yang terkandung dalam tafsir ini. Dengan menunjukkan keberadaan aspek modernitas yang terkandung dalam Tasir Rahmat berimplikasi pada kekhasan model penerjemahan dan penafsiran agar dapat menarik ketertarikan para peneliti selanjutnya.

Penelitian ini berangkat dari argumentasi bahwa keberadaan model dan cara yang sesuai dengan semangat modernitas dalam Tafsir Rahmat menunjukkan kebaharuan model penerjemahan dan penafsiran yang perlu ditelusuri lebih mendalam. Penelusuran atas aspek modernitasnya memberikan tambahan bagi perkembangan kajian tafsir di Indonesia dalam wilayah dialektika sains dan alQur'an. Pengungkapan atas dimensi ini juga dapat memunculkan ketertarikan bagi para pengkaji tafsir di Indonesia untuk meningkatkan dan mengenalkan kekhasan dalam Tafsir Rahmat. Diskusi dan dialektika yang intens terhadap tafsir ini dapat berimplikasi pada pengenalan lebih luas tentang kekhasan yang terkandung, sehingga berbagai konsep penafsiran yang dilakukan oleh para penafsir di Indonesia semakin berkembang dan tidak berjalan satu arah. Dialektika modernitas dan penafsiran perlu diungkapkan lebih lanjut untuk menggambarkan upaya para penafsir dalam meningkatkan pemahaman masyarakat yang lebih relevan dengan perkembangan ilmu pengetahuan.

Dalam proses pembuktian argumentasi tersebut, penelitian ini menggunakan metode kualitatif dengan jenis penelitian studi pustaka. Sumber data yang digunakan dalam penelitian ini terdiri dari dua sumber data, sumber data primer dan sekunder. Sumber data primer dalam penelitian ini didasarkan pada Tafsir Rahmat karya Oemar Bakry. Sedangkan sumber data sekunder yang digunakan dalam penelitian ini adalah hasil penelitian, dokumen, dan buku yang berkaitan dengan objek yang sedang dikaji. Cara dalam memperoleh data menempuh tiga proses, yakni reduksi data, display data, dan penarikan kesimpulan. Untuk memperdalam proses penarikan kesimpulan, penelitian ini menggunakan content analysis dalam proses analisa data. Segala bentuk proses metodis ini menjadi perangkat untuk membuktikan argumentasi yang telah ditetapkan.

\section{Biografi dan Konteks Historis Oemar Bakry}

Oemar Bakry lahir pada tanggal 26 Juni 1916 di Desa Kacang di pinggir Danau Singkarak Sumatra Barat. Masa ini bertepatan dengan perluasan gerakan pembaharuan Islam di Mesir yang dipelopori oleh Jamal al-Dīn al-Afghanī dan Muhammad Abduh ke wilayah Asia Tenggara termasuk di Sumatra Barat. Noer mengklaim pusat aktivitas pembaharuan Islam di Sumatra Barat berpusat di 
Padang. 9 Tahun lahir Bakry berada pada masa penguatan semangat pembaharuan yang dilancarkan melalui majalah al-Munir yang terbit dari tahun 1911 hingga 1918. Secara tegas, majalah ini bertujuan untuk memimpin dan membawa Muslim Melayu di Sumatera kepada kepercayaan dan praktik agama yang benar, memelihara kedamaian dan keharmonisan di antara sesama manusia, dan menerangi umat Muslim dengan pengetahuan dan kebijaksanaan..$^{10}$ Dengan tujuan tersebut, majalah al-Munir bermaksud untuk mengembalikan praktik Ibadah umat Islam sesuai dengan petunjuk-petunjuk yang bersumber dari al-Qur'an dan Hadis. Dalam konteks ini, semangat pluralitas dan pemurnian dalam praktik keagamaan di Sumatra Barat menjadi bagian dari perjuangan pembaharuan Islam.

Keterpengaruhan Bakry dalam gerakan ini dapat dilihat dari latar belakang pendidikannya sebagai lulusan dari sekolah Thawalib dan Diniyah Putra Padang Panjang. Ia lulus dari sekolah Diniyah pada tahun 1931 dan lulus di Thawalib pada tahun 1932. Dua sekolah ini merupakan sarana memperluas gerakan pembaharuan di Sumatra Barat yang sebelumnya berpusat di sekolah Adabiyah yang dipelopori oleh Abdullah Ahmad. Setelah sekolah Adabiyah ditutup karena intervensi Belanda, kalangan pembaharu muslim mendirikan sekolah lain yang lebih masif. Pada tahun 1915, Zainuddin Labai el-Yunusi mendirikan sekolah Diniyah dan dilanjutkan dengan pendirian Thawalib di Padang Panjang. ${ }^{11}$ Sekolah Thawalib pada perkembangan selanjutnya menjadi sebuah lembaga yang tersebar di seluruh Sumatera Barat. ${ }^{12}$ Sekolah tempat Bakry menuntut ilmu merupakan sekolah yang berperan pada masa itu sebagai media reformisme yang menyebarkan semangat pembaharuan dalam Islam. ${ }^{13}$

Keaktifan Bakry dalam menyebarkan semangat pembaharuan dan modernisme dalam Islam di Indonesia dibuktikan dengan pengabdiannya di lembaga-lembaga sekolah di Sumatera Barat. Ia tercatat menjadi guru di Sekolah Thawalib Padang pada tahun 1933 hingga 1936. Ia juga menjadi Direktur Sekolah Guru Muhammadiyah Padang Sidempuan tahun 1937 dan menjadi guru di sekolah Thawalib Padang Panjang pada Tahun 1938. Perannya dalam keilmuan dibuktikan dengan beragam karya yang telah diterbitkan, diantaranya: Uraian 50 Hadis, Memantapkan Rukun Iman dan Islam, al-Qur'an Mukjizat yang Terbesar,

\footnotetext{
${ }^{9}$ Deliar Noer, The Modernist Muslim Movement in Indonesia 1900-1942 (Kuala Lumpur: Oxford University Press, 1973), 30.

${ }^{10}$ Azyumardi Azra, "The transmission of al-Manar's reformism to the Malay-Indonesian world: The cases of al-Imam and al-Munir," Studia Islamika 6, no. 3 (1999): 94, https://doi.org/10.15408/sdi.v6i3.723.

${ }^{11}$ Jajat Burhanudin, Islam dalam Arus Sejarah Indonesia (Jakarta: Kencana, 2017), 398.

12 Taufik Abdullah, Sekolab dan Politik: Pergerakan Kaum Muda di Sumatra Barat 1927-1933, trans. oleh Muhammad Yuanda Zara (Yogyakarta: Suara Muhammadiyah, 2018), 36.

${ }^{13}$ Burhanudin, Islam dalam Arus Sejarah Indonesia, 399.
} 
Keharusan Memahami Isi al-Qur'an, Kebangkitan Umat Islam di Abad ke-XV H., dan Tafsir Rahmat. Selain itu, beberapa karyanya ditulis dalam bahasa Arab, seperti Tafsir Madrasi, Makarimul Akblak, dan al-Ahadisabibah.

\section{Harmonisasi al-Qur'an dan Sains dalam Tafsir Rahmat}

Kecenderungan modernitas dalam Tafsir Rabmat akan di tampilkan dalam bagian ini. Penjelasan atas kecenderungan modernitas penafsiran Oemar Bakry dijelaskan dalam 3 model. Model pertama penjelasan deskriptif yang mencakup bentuk modernitas dalam Tafsir Rahmat yang terwujud dalam dialektika antara sains dan al-Qur'an, fungsi sains dalam pembuktian kebenaran al-Qur'an, dan representasi sains dalam pemaknaan. Model kedua mengenai penjelasan kritis yang mencakup faktor yang menyebabkan adanya penjelasan dengan menggunakan ilmu pengetahuan dan teknologi. Model ketiga penjelasan transformatif yang mencakup dampak modernitas dalam reinterpretasi atas konsep-konsep aktual yang berkembang dalam ilmu pengetahuan modern.

\section{Bentuk Modernitas dalam Tafsir Rahmat}

Semangat modernitas dalam Tafsir Rahmat ditunjukkan oleh Bakry dengan menjadikan sains sebagai ukuran untuk membuktikan hikmah yang terkandung dalam larangan dan perintah Allah dalam al-Qur'an. Larangan dan kebolehan mengonsumsi makanan dianjurkan untuk di verifikasi melalui ilmu pengetahuan, baik pembuktian ilmiah melalui penelitian di laboratorium maupun pembuktian secara kejiwaan melalui psikologi. ${ }^{14}$ Bakry memberikan pembuktian dalam argumentasinya ini dengan memberikan contoh atas larangan Allah terhadap makanan, dan minuman. Kebolehan atas makanan tertentu mengandung pengertian bahwa makanan tersebut bermanfaat bagi kesehatan. Sedangkan larangan atas beberapa makanan mengindikasikan makanan tersebut tidak baik bagi tubuh manusia, seperti babi, anjing, dan darah. Mengenai makanan haram yang disebabkan penyembelihannya tidak menyebut nama Tuhan, dalam pandangan Bakry, bahaya yang ditimbulkan berupa gangguan pada jiwa, menyebabkan perasaan tidak senang, dan gangguan dalam pikiran. Segala macam dampak tersebut dapat hanya dapat dibuktikan melalui penalaran ilmiah menggunakan perangkat keilmuan modern. ${ }^{15}$ Hal yang sama dijelaskan oleh Bakry dalam memberikan hikmah dibalik pelarangan Allah atas khamr. ${ }^{16}$ Konsep larangan dalam al-Qur'an tidak hanya bernilai teologis akan tetapi larangan tersebut dapat dibuktikan secara ilmiah atas dampak yang dihasilkan.

\footnotetext{
${ }^{14}$ Oemar Bakry, Tafsir Rahmat (Jakarta: Mutiara, 1984), 49.

15 Bakry, 49.

${ }^{16}$ Bakry, 231.
} 
Kesesuaian kandungan al-Qur'an dengan perkembangan sains dan teknologi berdampak pada pembuktian dan penguatan atas kemukjizatan alQur'an. Perintah untuk memberikan susu eksklusif kepada anak selama dua tahun telah terbukti dengan beragam pandangan dokter bahwa Air Susu Ibu (ASI) memiliki kandungan yang dapat membantu memaksimalkan pertumbuhan anak. ${ }^{17}$ Dalam kasus pelarangan terhadap memakan binatang tertentu, Bakry menyarankan untuk membuktikan hikmah dibalik larangan tersebut melalui ilmu pengetahuan ${ }^{18}$. Hal yang sama juga dalam pembuktian terhadap nilai-nilai ketauhidan. ${ }^{19}$ Hal demikian berfungsi untuk memantapkan tauhid, kepercayaan kepada Allah dengan cara memikirkan dan mempelajari ciptaan Allah yang ada di alam semesta, baik ilmu tentang ruang angkasa, maupun segala ilmu yang membahas tentang materi-materi di muka bumi. Bagi Bakry, ilmu dan teknologi akan memberikan keyakinan bahwa Allah ada dan Maha Kuasa, serta kekuasaannya melebihi ilmu dan teknologi yang dihasilkan manusia. ${ }^{20}$ Ilmu dan teknologi menjadi sarana untuk menemukan hikmah dibalik perintah dan larangan Allah serta dapat memantapkan keimanan kepada Allah.

Realitas pemahaman yang berdasarkan pada perkembangan ilmu dan teknologi berdampak pada reaktualisasi atas makna setiap kata dalam al-Qur'an mengikuti istilah yang dikenal dalam keilmuan modern. Bakry memahami kata 'adhab dalam Q.S. al-An'am [6]: 65 dengan makna yang lebih luas yang mencakup segala bentuk kesengsaraan yang dialami manusia, baik disebabkan oleh bom atom, peluru kendali exocet, ranjau darat dan laut atau segala macam senjata mutakhir yang merupakan produk ilmu pengetahuan dan teknologi. ${ }^{21}$ Reaktualisasi makna dengan istilah modern dilakukan untuk memaknai kata kätib dalam Q.S. al-Baqarah [2]: 282 dengan makna akuntan, ${ }^{22}$ fähishah dalam Q.S. alNisā' [4]: 15 dimaknai lebih luas tidak hanya dalam konteks zina, akan tetapi juga homoseksual, ${ }^{23}$ dan kata samawät dalam Q.S. al-Baqarah [2]: 164 dengan makna ruang angkasa. Hal yang sama juga dilakukan oleh Bakry dalam memahami konsep-konsep hukum yang disesuaikan dengan keadaan masyarakat Indonesia, seperti memaknai kewajiban Haji yang disesuaikan dengan jarak Indonesia dengan Makkah ${ }^{24}$ dan pemaknaan atas bunga Bank. ${ }^{25}$ Ketertarikan Bakry terhadap sastra

\footnotetext{
${ }^{17}$ Bakry, 71.

${ }^{18}$ Bakry, 203.

19 Bakry, 47.

20 Bakry, 47.

${ }^{21}$ Bakry, 255.

22 Bakry, 89.

${ }^{23}$ Bakry, 151.

24 Bakry, 59.

25 Bakry, 87.
} 
juga tampak dalam pemahaman atas narasi al-Qur'an dengan menggunakan pribahasa, misalnya penggunaan "lain di mulut asing di hatinya", 26 "musang berbulu ayam" ${ }^{27}$ untuk menunjukkan makna kata munafik. Kecenderungan memahami al-Qur'an dalam konteks sosio-kesusasteraan (al-adabi al-ijtima’) yang relevan dengan masanya menunjukkan Bakry sebagai bagian dari mufasir modern.

\section{Faktor Modernitas dalam Tafsir Rahmat}

Kebutuhan untuk membuktikan narasi-narasi al-Qur'an dengan ilmu pengetahuan dan teknologi didorong oleh perintah Allah dalam berbagai ayatnya. Dalam konteks ini, Bakry memberikan argumentasi dalam pemahamannya terhadap Q.S. al-Baqarah [2]: 282 tentang indikasi bahwa narasi dalam surat tersebut mendorong umat Islam untuk melakukan pencatatan yang disesuaikan dengan kemajuan ilmu pengetahuan. ${ }^{28}$ Bagi Bakry, Ilmu pengetahuan dan teknologi menyediakan perangkat yang mendukung pemanfaatan nikmat Allah di muka bumi. Begitu juga perintah Allah untuk memikirkan dan memahami ruang angkasa dan seluruh isinya dapat menciptakan ilmu pengetahuan baru. Pemanfaatan ini mendorong umat Islam di masa kejayaannya untuk bergerak lebih maju dibandingkan dengan capaian yang dihasilkan oleh Barat. ${ }^{29}$ Bakry menempatkan al-Qur'an tidak hanya sekedar petunjuk dalam beribadah, akan tetapi sebagai pendorong untuk menciptakan dan meningkatkan kemajuan ilmu pengetahuan.

Petunjuk yang ada dalam al-Qur'an mengenai semangat ke arah pembentukan pengetahuan tidak banyak disadari karena kandungannya yang luas dan mendalam. Dalam konteks ini, Bakry memberikan solusi untuk memahami al-Qur'an dengan menggunakan ilmu pengetahuan sebagai sarana mengurai makna dalam setiap katanya. ${ }^{30}$ Dorongan untuk melakukan eksplorasi atas berbagai narasi yang berkaitan dengan ilmu pengetahuan juga memancing para ilmuan memahami al-Qur'an tidak hanya dalam posisinya sebagai teks sakral. Eksplorasi untuk menemukan petunjuk di dalamnya menuntut para pengkaji menggunakan perspektif sains modern sebagai perangkat analisa. ${ }^{31}$ Dengan mengutip al-A faghani, Bakry memberikan penjelasan tentang daya tarik al-Qur'an bagi para ilmuan,

Said Jamaluddin al-Afghany berkata, "Al-Qur'anul Karim tetap selalu seperti anake perawan". Artinya, selalu diingini oleh ilmuwan untuk menggali isinya. Al-Qur'anul Karim disebut suatu kitab suci yang sesuao dengan setiap tempat dan raman. Jadi tidak.

\footnotetext{
${ }^{26}$ Bakry, 9.

${ }^{27}$ Bakry, 169.

${ }^{28}$ Bakry, 89.

${ }^{29}$ Bakry, 13.

30 Bakry, xii.

${ }^{31}$ Bakry, xiv.
} 
akan basi, out of date. Hidayah dan petunjuknya tetap abadi sampai akbir zaman. Perkembangan ilmu dan teknologi sekarang banyak sekali mengungkapkan kebenaran ayat-ayat al-Qur'anul Karim. Menterjemabkan dan mentafsirkan al-Qur'anul Karim sekarang sudah jaub berbeda dengan dabulu sesuai dengan perkembangan ilmu dan teknologi ${ }^{32}$.

Penggunaan sains modern menjadi keharusan bagi Bakry untuk mengurai makna dan hikmah dibalik narasi al-Qur'an. Hal demikian menjadikan sains dan teknologi membawa dampak yang signifikan dalam memahami makna dalam suatu ayat agar petunjuk di dalamnya dapat dipahami untuk kemajuan pengetahuan pada era selanjutnya.

Fungsi sains dan teknologi sebagai sarana pemahaman tidak mengindikasikan pemahaman harus tunduk terhadap konsep yang terkandung di dalamnya. Bagi Bakry, kemutlakan kebenaran al-Qur'an justru menjadikan ilmu pengetahuan tunduk atas narasi yang terkandung di dalamnya. ${ }^{33}$ Dalam kata pengantar Tafsir Rahmat, Bakry menjelaskan,

Bukan al-Qur'an yang harus tunduk dan disesuaikan dengan ilmu dan teknologi, tetapi sebaliknya. Jika ilmu dan teknologi berbeda isi al-Qur'anul Karim, maka kesalahan harus dicari pada ilmu dan teknologi itu. Ilmu dan teknologi harus membuktikan kebenaran isi al-Qur'anul Karim. Memang ilmu dan teknologi ada yang salah. Yang diduga benar dan tepat, kemudian ternyata salah. Al-Qur'anul Karim bukan begitu. Isinya tetap benar sampai di akbir zaman. Kebenaranny mutlak (absolut).

Kebenaran kandungan al-Qur'an menjadi kontrol atas validitas perkembangan sains modern. Bakry memberikan argumen yang khas dengan meletakkan fungsi sains dan teknologi sebagai alat untuk memahami al-Qur'an sekaligus al-Qur'an memberikan konfirmasi atas kebenaran capaian sains dan teknologi.

\section{Implementasi Modernitas dalam Penafsiran}

Konsep pengetahuan yang dimiliki oleh penafsir berpengaruh pada penggunaan narasi penafsiran yang identik dengan latar belakang kehidupan penafsir. Data menunjukkan terdapat tiga transformasi pemaknaan dalam Tafsir Rahmat, penerimaan atas konsep pluralitas dalam masyarakat Indonesia, progresivitas atas tradisi masyarakat Indonesia, dan reinterpretasi atas makna jihad dalam konteks Indonesia. Pertama, kecenderungan Bakry terhadap keniscayaan hidup berdampingan dengan non-muslim ditunjukkan dalam pemahaman atas

\footnotetext{
32 Bakry, xiv.

33 Bakry, xiv.
} 
Q.S. Ali Imran [3]: 28-32. Larangan untuk menjadikan kalangan non-muslim sebagai teman akrab, pelindung, pemimpin, penolong, dan sebagainya, didorong oleh upaya yang dilakukan oleh kaum musyrik terhadap Nabi Muhammad pada masa awal dakwah. Realitas semacam itu bagi Bakry menjadi hal yang sewajarnya. Akan tetapi, dalam konteks negara yang merdeka dan Islam yang kuat, menjadikan kalangan non-muslim sebagai teman tidak dilarang. ${ }^{34}$ Sedangkan perintah berperang dalam Islam tidak ditujukan untuk memaksa kaum musyrik untuk masuk Islam. Perang ditujukan untuk menciptakan keadaan yang bebas bagi setiap orang untuk memilih agama yang diyakininya. Tugas seorang muslim hanya menyampaikan kebenaran dan tidak memaksakan keyakinan. ${ }^{35}$ Perbedaan kalangan muslim dan non-muslim hanya terletak pada penguasaan mereka terhadap ilmu pengetahuan, bukan hal lainnya. ${ }^{36}$ Kerukunan menjadi point utama dalam pandangan Bisry untuk menciptakan suasana yang damai yang justru menjadi tujuan utama Islam.

Kedua, progresivitas dalam pemahaman yang dibawa Bakry berdampak pada upaya untuk melakukan pemurnian atas sikap keagamaan yang dipandang tidak sesuai dengan al-Qur'an. Bakry memberikan pemahaman makna syafaat sebagai pembelaan agar orang yang berdosa diringankan dosanya. ${ }^{37}$ Ia juga memberikan pemahaman wasilah sebagai anjuran untuk mengikuti al-Qur'an dan sunnah Rasulullah. ${ }^{38}$ Dengan pemahaman demikian, Bakry memberikan larangan bagi siapapun untuk meminta syafaat dari guru, wali, tempat sakti, apa saja yang dianggap keramat. ${ }^{39} \mathrm{Hal}$ demikian baginya merupakan tindakan yang keluar dari ajaran agama Islam, ${ }^{40}$ karena setiap orang menanggung sendiri amal baik dan buruknya. ${ }^{41}$ Seseorang yang melakukan amal dan perjuangan yang ulet karena Allah akan dapat memperoleh kebahagiaan. ${ }^{42}$ Sedangkan bagi orang yang berbuat buruk, maka ia tidak akan mendapatkan pertolongan, baik dengan syafaat ${ }^{43}$ maupun dengan wasilah. ${ }^{44}$ Perilaku meminta syafaat dan wasilah kepada sesuatu selain Allah merupakan perbuatan yang menyimpang, sehingga perlu dilakukan pemurnian pemahaman.

Ketiga, pemahaman atas narasi jihad dalam al-Qur'an diarahkan pada pemahaman dalam konteks negara atau masyarakat yang damai. Hal ini dapat

\footnotetext{
${ }^{34}$ Bakry, 101.

${ }^{35}$ Bakry, 341.

${ }^{36}$ Bakry, 15.

${ }^{37}$ Bakry, 17.

${ }^{38}$ Bakry, 213.

${ }^{39}$ Bakry, 17.

${ }^{40}$ Bakry, 213.

${ }^{41}$ Bakry, 17.

42 Bakry, 41.

43 Bakry, 17.

${ }^{44}$ Bakry, 213.
} 
dilihat dari pemaknaan Bakry terhadap perang dalam Islam yang dianggap sebagai upaya untuk mempertahankan diri, bukan untuk memaksa orang lain masuk Islam. ${ }^{45}$ Jihad, dalam pandangan Bakry tidak hanya bermakna perang, tetapi maknanya meliputi berbagai cara untuk membela agama Allah, seperti berdakwah, infak, al-amr bi al-ma'ruf wa naby 'an al-munkar dan memerangi hawa nafsu. ${ }^{40}$ Sedangkan makna fi sabil Allah, oleh Bakry dipahami sebagai upaya yang dilakukan seseorang yang berkaitan dengan pemenuhan keperluan orang banyak, seperti membangun masjid, sekolah, jembatan rumah sakit, dan panti asuhan. ${ }^{47}$ Dalam konteks masyarakat muslim minoritas, jika mereka terancam, al-Qur'an tidak memerintahkan untuk melawan dengan berperang, akan tetapi menganjurkan untuk berpindah sebagaimana yang disebutkan dalam Q.S. al-Nisā’ [4]: $97 .{ }^{48}$ Keniscayaan perdamaian bagi umat Islam justru terkandung dalam al-Qur'an yang ditunjukkan oleh ayat-ayat yang menyebutkan redaksi jihad.

\section{Modernitas dalam Pemahaman al-Qur'an: Dialektika Sains, Agama, dan Tradisi}

Penelitian ini memperlihatkan bahwa problem akademik yang terkandung dalam Tafsir Rahmat karya Oemar Bakry tidak hanya terbatas pada kebutuhan untuk mengungkapkan metode dan corak yang digunakan. Pengungkapan atas narasi penerjemahan dan penafsiran dengan menggunakan kemajuan sains dan teknologi yang terkandung dalam tafsir ini lebih dibutuhkan untuk didalami. Bakry meletakkan sains dan teknologi tidak hanya sebagai perangkat pemahaman, tetapi sekaligus sebagai sarana konfirmatif dan validatif. Sains memberikan penjabaran yang lebih mendalam terhadap kandungan dan hikmah dalam setiap ayat. Begitu juga sebaliknya, al-Qur'an menjadi verifikator terhadap kebenaran capaian ilmu pengetahuan. Dalam aspek lain, Bakry juga memberikan penekanan terhadap dialektika tradisi dan al-Qur'an. Menurutnya, tradisi menjadi kontrol atas pemahaman al-Qur'an dengan memberikan diksi yang relevan dengan perkembangan tradisi. Al-Qur'an juga mengontrol tradisi agar tetap sesuai dengan perintah dan kandungan ayat-ayatnya, sehingga hal yang tidak sesuai dari tradisi harus ditinggalkan. Bentuk penafsiran demikian mengindikasikan kandungan Tafsir Rahmat melampaui batasan metodologis yang menjadi pusat perhatian para peneliti sebelumnya.

Pengungkapan semangat modernitas dalam penafsiran yang dilakukan Bakry memberikan penekanan pada pengelompokan tafsir ini sebagai bagian dari

\footnotetext{
45 Bakry, 167.

46 Bakry, 127.

${ }^{47}$ Bakry, 83.

48 Bakry, 175.
} 
tafsir modern. Kajian yang telah ada cenderung meletakkan gagasan Bakry dalam memahami ayat dalam kategori modern didasarkan pada masa produksi dan latar belakang penulisannya. Gusmian memasukkan Tafsir Rabmat sebagai tafsir yang berada pada periode kedua (1970-1980) dengan sistematika penafsiran 30 juz. ${ }^{49}$ Sedangkan dalam penelitian lainnya, Gusmian mengklaim tafsir ini sebagai bagian dari tafsir yang diproduksi oleh seorang yang aktif dilingkungan madrasah. ${ }^{50}$ Penelusuran atas gagasan yang terkandung di dalamnya justru diabaikan untuk menjadi dasar identifikasi Tafsir Rabmat sebagai bagian dari tafsir modern. Gusmian mengklaim tipologi yang dibuat untuk menyempurnakan periodisasi yang dibuat oleh Federspiel. ${ }^{51}$ Akan tetapi, jika meninjau kandungan dan ciri khas dari tafsir ini, justru periodisasi Gusmian lebih mengacaukan. Tipologi Federspiel justru mendapatkan argumentasi penguat dengan memasukkan Tafsir Rahmat sebagai bagian dari upaya meletakkan al-Qur'an sebagai kitab suci yang berasal langsung dari Tuhan. ${ }^{52}$ Pandangan ini dapat ditunjukkan dengan pendapat Bakry yang menekankan pada kemutlakan kandungan al-Qur'an yang mengontrol tradisi dan sains. Kekurangan dari Federspiel terdapat pada pengabaiannya terhadap fungsi sains dan respons Bakry terhadap tradisi yang menjadi ciri khas pemikiran modern. Hal yang sama diungkapkan Aigbodioh yang menyebutkan bahwa modernitas selalu memperselisihkan kandungan tradisi yang menyalahi semangat ilmu pengetahuan. ${ }^{53}$ Dalam perspektif agama, modernitas selalu memosisikan sebagai lawan dari tradisi yang dianggap tidak merepresentasikan kandungan agama yang sebenarnya. Perbedaan tipologi dalam kajian tafsir di Indonesia menjadi bukti atas sifat prematur pemetaan yang dilakukan oleh para peneliti terhadap kajian tafsir di Indonesia.

Sifat prematur dalam pemetaan kajian tafsir berdampak pada pengabaian atas gagasan dan kekhasan yang terkandung dalam narasi penyampaiannya. Gagasan Bakry dalam Tafsir Rahmat memberikan peluang bagi pengkaji tafsir untuk menemukan unsur baru demi pembangunan konsep metodologi penafsiran di Indonesia. Pilihan untuk menggunakan istilah-istilah modern yang digunakan dalam keilmuan sains dan teknologi berdampak pada gaya baru dalam proses penerjemahan. Terjamah tidak hanya menjadi proses pengalihan bahasa dengan mengikuti struktur bahasa aslinya dengan padanan kata yang baku, tetapi menjadi alat untuk mengenalkan padanan istilah modern yang relevan dengan makna kata

${ }^{49}$ Islah Gusmian, Khazanah Tafsir Indonesia, dari Hermeneutika Hingga Ideologi (Yogyakarta: LKiS, 2013), 62.

${ }^{50}$ Gusmian, “Tafsir al-Qur'an di Indonesia: Sejarah dan Dinamika."

${ }^{51}$ Gusmian, Khazanah Tafsir Indonesia, dari Hermeneutika Hingga Ideologi, 59.

${ }^{52}$ Howard M. Federspiel, Kajian al-Qur'an di Indonesia: dari Mabmud Yunus bingga Qurasih Shibab, trans. oleh Tajul Arifin (Bandung: Mizan, 1996), 120.

${ }^{53}$ Jacob A. Aigbodioh, "A Response to Helen Lauer's Critique of the Tradition Versus Modernity Dichotomy," Kamla Raj Enterprises 9, no. 2 (2017): 79-85, https://doi.org/10.1080/0972639X.2011.11886630. 
dalam al-Qur'an. Penerjemahan kata al-samä' dengan makna ruang angkasa memberikan dampak pemahaman yang lebih luas tentang maksud yang hendak dituju oleh kata tersebut. Hal yang sama juga dijelaskan oleh Campanini yang menyebutkan bahwa penjelasan yang mengacu pada aspek modernitas memberikan pemahaman yang lebih menyeluruh terhadap al-Qur'an. ${ }^{54}$ Upaya Bakry untuk merelevansikan pemahaman terhadap kata dalam al-Qur'an menunjukkan perkembangan dalam sistem penerjemahan yang diabaikan dalam kajian tafsir Indonesia.

Beragam studi terdahulu hanya menyebutkan Tafsir Rahmat sebagai bagian pelengkap dari tipologi penafsiran di Indonesia dengan mengabaikan kandungan penjelasan dan sistem penerjemahan. Aspek metode ${ }^{55}$ dan klasifikasi berdasarkan masa hidup Bakry ${ }^{56}$ dan masa produksi tafsir ini lebih dibanyak ketimbang pengungkapan penggunaan sains sebagai dasar penerjemahan dan semangat pembaharuan sebagai dasar pemahaman. Pembahasan atas konteks hanya dilakukan oleh Federspiel, tetapi identifikasinya hanya didasarkan pada pandangannya terhadap otentisitas al-Qur'an sebagai firman Allah. ${ }^{57}$ Hal yang penting dalam kandungan penafsiran dan sistem penerjemahan ditinggalkan oleh banyak peneliti. Bakry justru memberikan model penerjemahan baru yang tidak dilakukan sebelumnya dengan menggunakan istilah modern dalam menerjemahkan ayat. Begitu juga, pengungkapan atas semangat untuk menemukan pengetahuan baru melalui gambaran yang diberikan Allah dalam alQur'an menjadi perhatiannya. Relasi sains dengan al-Qur'an yang digunakan Bakry mengindikasikan proses dialektis antara sains dan al-Qur'an dalam menemukan gagasan utamanya. Realitas kemasyarakatan (tradisi) juga diperhatikan sebagai bagian dari kecenderungannya terhadap semangat modernisasi dalam pemahaman keagamaan. Aspek inilah yang ditinggalkan oleh para peneliti terdahulu yang menjadikan Tafsir Rabmat kurang populer bagi para peneliti tafsir di Indonesia.

Pengabaian terhadap Tafsir Rahmat dalam penelitian berdampak pada popularitas tafsir ini dalam bidang akademik berkurang dibandingkan tafsir-tafsir lainnya. Kajian tafsir yang terkesan satu arah menjadikan popularitas karya tafsir tidak berimbang. Diskusi dan dialektika hasil penelitian atas satu tafsir dalam kajian akademis dapat meningkatkan pengenalan atas kandungan penafsiran dan

${ }^{54}$ Massimo Campanini, The Qur'an: The Basics, trans. oleh Oliver Leaman (London: Routledge, 2016), 101.

55 Adekayanti, "Metodologi Penafsiran Oemar Bakry (Studi Kitab Tafsir Rahmat)."

${ }^{56}$ Gusmian, Khazanah Tafsir Indonesia, dari Hermeneutika Hingga Ideologi; Gusmian, "Tafsir al-Qur'an di Indonesia: Sejarah dan Dinamika."

${ }^{57}$ Federspiel, Kajian al-Qur'an di Indonesia: dari Mahmud Yunus bingga Qurasib Shihab. 
popularitas tafsir berserta mufasirnya. Popularitas ini akan mendistorsi kandungan dan pola penafsir lainnya yang tidak dikenal, sehingga berpotensi pada penyempitan konsep penafsiran di Indonesia secara umum. Hal yang sama disebutkan Annisa bahwa produksi besar-besaran terhadap suatu ide rentan untuk menjadikan ide tersebut sebagai bagian dari identitas perorangan maupun kelompok. ${ }^{58}$ Pengkajian yang tidak seimbang terhadap suatu karya tafsir juga berdampak pada kajian atas tafsir Indonesia yang cenderung repetitif. Kajian lebih banyak dilakukan pada karya-karya tafsir yang telah banyak dikenal sebelumnya, seperti Tafsir al-Azhar, Tafsir al-Misbah, Tasir an-Nuur, dan Tafsir al-Furqan. Pengkajian atas tafsir ini pada dasarnya tidak menyalahi etika akademis sepanjang kebaharuan penelitian menjadi dasar utamanya. Hal ini berarti bahwa pengungkapan atas kandungan tafsir di Indonesia masih belum selesai. Akan tetapi, penjelasan dengan hanya melakukan pengkajian atas tafsir-tafsir tertentu telah mengabaikan produk tafsir lain. Eksplorasi terhadap sistem penerjemahan dan kandungan penjelasan dalam suatu tafsir yang belum dilakukan sebelumnya diperlukan. Hal ini tidak hanya bertujuan untuk melakukan pendalaman dan mengungkapkan kekhasan tafsir di Indonesia, akan tetapi untuk mengenalkan lebih jauh produk tafsir yang sedang diteliti.

\section{Kesimpulan}

Pengabaian terhadap Tafsir Rabmat dalam banyak penelitian tidak menunjukkan kandungan penafsiran dalam karya ini tidak memiliki kekhasan dan kebaharuan. Penelitian ini justru menunjukkan aspek kebaharuan dalam sistem penerjemahan dan penafsiran yang mengadopsi perkembangan sains dan teknologi. Ketertarikan Bakry terhadap unsur modernitas cenderung diabaikan, sehingga popularitas karya ini tidak seperti karya lain yang sejenis, seperti Tafsir Quran Karim karya Mahmud Yunus, dan Tafsir al-Furqan karya A. Hassan. Penerjemahan yang dilakukan Bakry tidak mengikuti sistem penerjemahan karya sebelumnya yang cenderung menampilkan makna kata sesuai padanannya dalam bahasa Indonesia. Bakry justru memberikan makna yang berlaku dalam sains. Model penerjemahan yang demikian lebih representatif untuk memberikan pemahaman atas padanan makna kata yang sudah dikenal oleh masyarakat modern. Demikian juga, dalam aspek penjelasan atas maksud sebuah ayat yang menggunakan realitas modern sebagai gambarannya. Sebagai bagian dari tokoh pembaharu, Bakry juga memberikan komentar atas problem tradisi yang masuk dalam praktik ibadah. Ia memberikan kritik atas problem tersebut yang mencerminkan semangat pembaruan yang dibawa dalam proses pemahaman terhadap al-Qur'an. Beragam konsep dan cara yang dijelaskan menguatkan bahwa

${ }^{58}$ Firly Annisa, "Hijrah Milenial: Antara Kesalehan dan Populism," MAARIF 13, no. 1 (2018): 38-54, https://doi.org/10.47651/MRF.V13I1.11. 
al-Qur'an merupakan petunjuk yang relevan dalam segala konteks yang selalu berkembang.

Penemuan atas unsur ini tidak menjadikan problematika atas Tafsir Rahmat diakomodasi seluruhnya dalam penelitian ini. Penelitian ini hanya mengambil batasan dialektika tradisi, modernitas, dan al-Qur'an. Aspek lain yang berkaitan dengan gagasan pembaharuan yang mengarah pada puritanisme ditinggalkan. Aspek-aspek tersebut menjadi ruang baru bagi para peneliti selanjutnya untuk mengidentifikasi kekayaan kandungan dalam tafsir ini. Begitu juga, indentifikasi atas modernitas dalam Tafsir Rahmat yang ditunjukkan dalam penelitian ini dikritisi agar dialektika antar peneliti dapat berlangsung. Dialektika hasil penelitian dapat mengantarkan intensitas kajian atas tafsir ini, sehingga dapat mempopulerkan Tafsir Rahmat dalam perbincangan akademik dan memberikan sumbangsih bagi perkembangan metode penafsiran di Indonesia.

\section{Bibliografi}

Abdullah, Taufik. Sekolah dan Politik: Pergerakan Kaum Muda di Sumatra Barat 1927. 1933. Diterjemahkan oleh Muhammad Yuanda Zara. Yogyakarta: Suara Muhammadiyah, 2018.

Adekayanti, Sri. "Metodologi Penafsiran Oemar Bakry (Studi Kitab Tafsir Rahmat).” UIN Sunan Kalijaga Yogyakarta, 2007.

Aigbodioh, Jacob A. "A Response to Helen Lauer's Critique of the Tradition Versus Modernity Dichotomy." Kamla Raj Enterprises 9, no. 2 (2017): 79_ 85. https://doi.org/10.1080/0972639X.2011.11886630.

Annisa, Firly. "Hijrah Milenial: Antara Kesalehan dan Populism." MAARIF 13, no. 1 (2018): 38-54. https://doi.org/10.47651/MRF.V13I1.11.

Aziz, Thoriqul, Ahmad Zainal Abidin, dan Muthmainnatun Nafiah. "Tafsir Nusantara dan Isu-isu Global: Studi Kasus Relevansi Pemikiran Hamka tentang Keadilan Sosial, Kesetaraan Gender dan Pluralisme.” Refleksi 19, no. 2 (30 November 2020). https:/ /doi.org/10.15408/REF.V19I2.16791.

Azra, Azyumardi. "The transmission of al-Manar's reformism to the MalayIndonesian world: The cases of al-Imam and al-Munir." Studia Islamika 6, no. 3 (1999): 75-100. https:// doi.org/10.15408/sdi.v6i3.723.

Baihaki, Egi Sukma. "Penerjemahan Al-Qur'an: Proses Penerjemahan al-Qur'an di Indonesia." Jurnal Ushuluddin 25, no. 1 (2017): 44. https://doi.org/10.24014/jush.v25i1.2339.

Bakry, Oemar. Tafsir Rahmat. Jakarta: Mutiara, 1984.

Burhanudin, Jajat. Islam dalam Arus Sejarah Indonesia. Jakarta: Kencana, 2017. 
Campanini, Massimo. The Qur'an: The Basics. Diterjemahkan oleh Oliver Leaman. London: Routledge, 2016.

Farooqui, N. K., Mohammed Fauzan Noordin, dan Roslina Othman. "Ontology matching: A case of English translation of Al-Quran Tafsir." In Proceedings - International Conference on Information and Communication Technology for the Muslim World 2018, ICT4M 2018, 1-6. Institute of Electrical and Electronics Engineers Inc., 2018. https://doi.org/10.1109/ICT4M.2018.00010.

Federspiel, Howard M. Kajian al-Qur'an di Indonesia: dari Mabmud Yunus bingga Qurasib Shibab. Diterjemahkan oleh Tajul Arifin. Bandung: Mizan, 1996.

Gusmian, Islah. Khazanah Tafsir Indonesia, dari Hermeneutika Hingga Ideologi. Yogyakarta: LKiS, 2013.

"Tafsir al-Qur'an di Indonesia: Sejarah dan Dinamika." Nun: Jumal Studi Alquran dan Tafsir di Nusantara 1, no. 1 (2015). https://doi.org/10.32459/NUN.V1I1.8.

Hussin, Mohamad, dan Muhammad Hakim Kamal. "Translation of al-Quran into Malay Language in the Malay World." IJISH (International Journal of Islamic Studies and Humanities) 4, no. 1 (2021): 32-50. https://doi.org/10.26555/IJISH.V4I1.3322.

Latif, Abd. "Spektrum Historis Tafsir al-Qur'an di Indonesia." At-Tibyan 3, no. 1 (2020): 55-69. https://doi.org/10.30631/ATB.V3I1.14.

Noer, Deliar. The Modernist Muslim Movement in Indonesia 1900-1942. Kuala Lumpur: Oxford University Press, 1973.

Sayyida, Sayyida, Kusmana Kusmana, Eva Nugraha, Hamka Hasan, Yudi Setiadi, dan Rahman Ahdori. "Literature Qur'an in Indonesia: Tafsir Al-Qur'an H. Zainuddin Hamidy And Fachruddin HS (Has Analysis Of The Philological Approach)." In ICIIS. Jakarta, 2020. https://doi.org/10.4108/EAI.20-10-2020.2305183.

Tamam, Ahmad Badrut. "Model Penelitian Tafsir; Studi Karya Howard M. Federspiel:" Madinah: Jurnal Studi Islam 5, no. 2 (2018): 125 - 138-125 138.

http://ejournal.iaitabah.ac.id/index.php/madinah/article/view/275. 